\title{
Review
}

\section{The In Vivo Pig-a Gene Mutation Assay}

\author{
Daishiro Miura ${ }^{1}$
}

Pharmaceutical Development Research Laboratories, Teijin Institute for Bio-medical Research, Teijin Pharma Limited, Tokyo, Japan

Received October 1, 2014; Revised October 7, 2014; Accepted October 7, 2014

J-STAGE Advance published date: October 10, 2014

The phosphatidylinositol glycan anchor biosynthesis, Class A gene (Pig-a in rodents, PIG-A in humans) codes for a catalytic subunit of the $\boldsymbol{N}$-acetylglucosamine transferase complex that is involved in an early step of glycosylphosphatidyl inositol (GPI) anchor synthesis, and GPI anchors tether specific protein markers to the surface of various types of cells. Two distinct strategies for Pig-a gene mutation assay used peripheral blood have been developed, one using flow cytometry and the other using limiting-dilution cloning. The limiting-dilution cloning assay using bacterial protoxin, proaerolysin, as a selective agent is resource intensive. For routine analysis of mutant frequency, the flow cytometric procedures employing fluorescently labeled antibodies against GPI-anchored markers (e.g., anti-CD59 for rat red blood cells, anti-CD24 for mouse red blood cells) are preferred for routine analysis of mutant frequency. The advantage of the cloning assay, however, is in-depth analyses of the mutant genotype (mutational spectra analysis). The characteristics of the flow cytometric Pig-a gene mutation assays, i.e., induced Pig-a mutant frequencies were persistence and the effect of split doses of chemicals were additive, make the assay on reticulocytes and total red blood cells an attractive possibility for developing detailed mutagenicity data in vivo. Although a large amount of information must be gathered on assay performance, progress toward the goal in the last few years has been rapid, and multi-laboratory trial has been initiated and ongoing.

Key words: phosphatidylinosital glycan anchor biosynthesis Class A gene, glycosylphosphatidyl inositol-anchor, flow cytometry

\section{Introduction}

The identification of human genotoxic hazard is an important step in the development of pharmaceuticals. To this end, genotoxicity testing is performed to ensure safety during clinical trials and during the treatment of general patient populations (1). The core test battery for hazard identification, agreed upon by regulatory agencies and pharmaceutical companies from the United States, the European Union, and Japan, consists of a series of in vitro and in vivo genotoxicity assays. It is generally agreed, however, that the ability of the battery to predict carcinogenicity (a principal application of the battery) is less than perfect $(2,3)$. One possible reason for this is that the gene mutation assays that are part of the battery, i.e., the bacterial reverse mutation and the mouse lymphoma assays, are in vitro tests. In vitro assays do not replicate the metabolism and pharmacodynamics that occur in vivo, and this deficiency may negatively impact the predictive ability of the battery.

The last decade has seen the emergence of a new in vivo gene mutation assay based on the phosphatidylinositol glycan anchor biosynthesis, Class A gene (Pig- $a$ in rodents, $P I G-A$ in humans). The Japanese collaborative research group in the Japanese Environmental Mutagen Society (JEMS) has played an important role in the development of this assay, and it seems fitting that a collection of papers to familiarize readers with recent advances by the collaborative research group would appear in a special issue of the JEMS journal, Genes and Environment.

\section{The Pig-a Gene}

The Pig- $a$ codes for a catalytic subunit of the $N$ acetylglucosamine transferase complex that is involved in an early step of glycosylphosphatidyl inositol (GPI) anchor synthesis (4-7), and GPI anchors tether specific protein markers to the surface of various types of cells (e.g., hematopoitic cells) in several animal species, including rodents and humans $(8,9)$. Much of what is known about Pig- $a$ mutation has been derived from research on a rare, acquired genetic disease in human, paroxysmal nocturnal hemoglobinuria (PNH). Although several genes besides $P I G-A$ are required for GPI synthesis (e.g., $P I G-B$ and $P I G-C$, Fig. 1) and silencing of genes in the anchor synthesis pathway has

\footnotetext{
${ }^{1}$ Correspondence to: Daishiro Miura, Toxicology Research Department, Pharmaceutical Development Research Laboratories, Teijin Institute for Bio-medical Research, Teijin Pharma Limited, 4-3-2, Asahigaoka, Hino, Tokyo 191-8512, Japan. Tel: +81-42-586-8962, Fax: +81-42-587-5520, E-mail: d.miura@teijin.co.jp doi: org/10.3123/jemsge.2014.027
} 


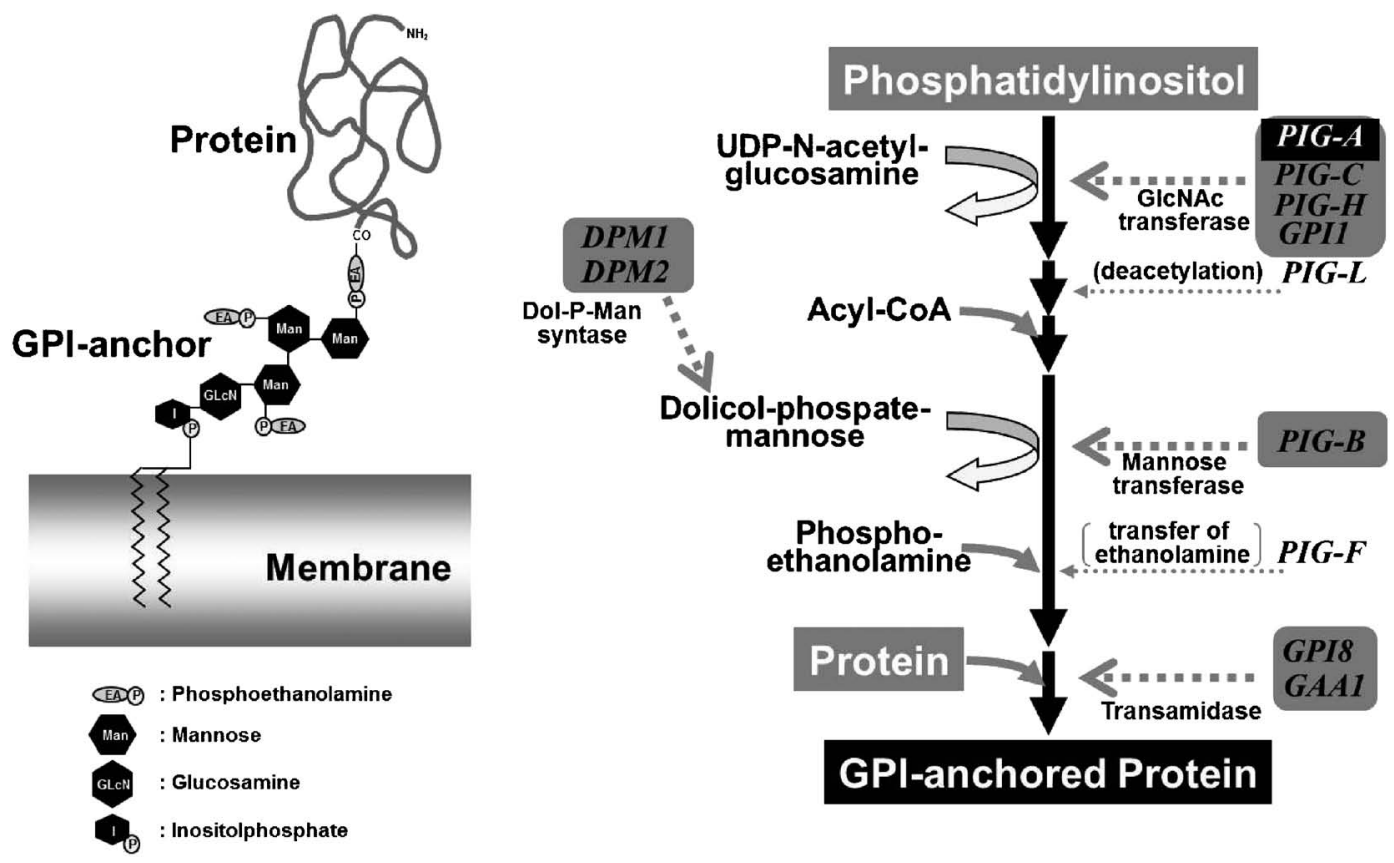

Fig. 1. Structure and synthesis of GPI-anchored protein.

been known to occur (10), a GPI-deficient phenotype occurs in patients with $\mathrm{PNH}$ and its basis is mutation of the $P I G-A(6,7)$. Only the $P I G-A$, as well as Pig- $a$ in rodents, is located on the $\mathrm{X}$ chromosome $(4,11)$, and being on the $\mathrm{X}$-chromosome means that a single mutation can inactivate the enzymatic function of the $P I G-A$ or Pig- $a$ protein and disrupt anchor synthesis. Thus, the GPI anchor-deficient phenotype appears to be virtually equivalent to PIG-A mutation, and by analogy, Pig- $a$ mutation. The preferred method for diagnosing $\mathrm{PNH}$ is currently the staining of peripheral blood with fluorescently labeled antibodies against GPI-anchored markers, e.g., CD55 and CD59, followed by measuring the fraction of marker-deficient cells by flow cytometry (12).

\section{The In Vivo Pig-a Gene Mutation Assay}

$P i g-a$ was first suggested as a possible reporter of in vivo gene mutation by Araten et al. (13). Two distinct strategies for Pig- $a$ gene mutation assay used peripheral blood have been developed, one using flow cytometry and the other using limiting-dilution cloning. Flow cytometry-based methods, which are derived from techniques used to diagnose PNH, employ fluorescently labeled antibodies against GPI-anchored markers (e.g., anti-CD59 for rat red blood cells (RBCs), anti-CD24 for mouse RBCs) and/or flow cytometry strategies for focusing the analysis on the cells of interest. In earlier work, for instance, light scattering was used to distinguish cells from platelets and an antibody specific for white blood cells was used to enrich the cell population for RBCs (14), or a nucleic acid stain was used to distin- guish reticulocytes (RETs) from normochromatic erythrocytes (NCEs) (15). Kimoto et al. developed the method that facilitates measuring mutant frequencies in early arising populations of blood cells, bone marrow erythroids (BMEs) and RETs (PIGRET assay) $(16,17)$. BMEs were identified using an antibody against rat erythroid-specific marker, HIS49, and RETs were selectivity enriched from peripheral blood using magnetic separation of cells positive for CD71, a transferrin receptor expressed on the surface of RETs, but not on the surface of mature RBCs. All the Pig- $a$ gene mutation assays described to date have used either peripheral blood cells or bone marrow cells. The main reason for this is that it is difficult to process solid tissues to produce sufficient numbers of single cells with intact cell surfaces to adopt flow cytometry strategies. Protocols for the dissociation of tissues into individual cells typically call for digestion of intercellular linkages, and such treatments may damage either the GPI anchors or GPI-anchored markers used in the detection of Pig- $a$ gene mutation, artificially inflating the fraction of mutant cells.

An alternative approach for measuring Pig- $a$ gene mutation used limiting-dilution clonal growth of Pig-a mutant GPI-deficient T-cells in the presence of the bacterial protoxin, proaerolysin (ProAER) (18). T-cells convert ProAER to a toxin (aerolysin) that binds directly to GPI anchors, resulting in a disruption of membrane integrity and cell death $(19,20)$. Pig- $a$ mutants, lacking GPI anchors, expand in the presence of the toxin to form clones in 96-well plates. The method for con- 
ducting limiting-dilution cloning assay using ProAER as a selective agent are analogous to how the Hprt lymphocyte mutation assay is performed using 6-thioguanine selection. The cloning assay for Pig- $a$ gene mutation, like the similar Hprt lymphocyte assay, is resource intensive. For routine analysis of mutant frequency and experiments requiring the analysis of large numbers of animals, therefore, the flow cytometric procedures are preferred. The main advantage of the cloning assay, however, is that it is a ready source of growing, nucleated Pig- $a$ mutant cells on which in-depth analyses of the mutant genotype, i.e., mutational spectra analysis, and phenotype can be performed. Miura et al. showed that ProAER-resistant T-cells from $N$-ethyl- $N$-nitrosourea (ENU)-treated rats had a mutation spectrum characteristic of the DNA damage produced by ENU and very similar to the mutation spectrum produced by ENU in the rat T-cell Hprt assay (Table 1) (21). These data established the mutational basis (i.e., alteration to DNA sequence) for the ProAER-resistant phenotype in rat Tcells, and by analogy, the CD48-negative phenotype in the rat flow cytometric T-cell assay (18) and the CD59negative phenotype in the flow cytometric rat RBC assay (14). As for more convincing support for the Pig-a mutational basis of the flow cytometric RBC assay, Kimoto et al. reported an ENU-specific mutation spectrum in nucleated erythroid cells sorted by flow cytometry from the bone marrow of ENU-treated mice (16).

Table 1. Comparison of independent Pig- $a$ and Hprt mutations found in ProAER-resitant and 6-thioguanine-resistent clones from ENU-treated Fisher 344 rats (21)

\begin{tabular}{|c|c|c|c|c|}
\hline \multirow{2}{*}{$\begin{array}{l}\text { Sequence } \\
\text { alteration }\end{array}$} & \multicolumn{2}{|c|}{ Pig- $a$ mutations } & \multicolumn{2}{|c|}{ Hprt mutations ${ }^{\S}$} \\
\hline & Number* & Percentage $^{\dagger}$ & Number* & Percentage \\
\hline \multicolumn{5}{|c|}{ Basepair substitution } \\
\hline $\mathrm{G}: \mathrm{C} \rightarrow \mathrm{A}: \mathrm{T}$ & 5 & $10 \%$ & 7 & $10 \%$ \\
\hline $\mathrm{A}: \mathrm{T} \rightarrow \mathrm{G}: \mathrm{C}$ & 9 & $18 \%$ & 17 & $25 \%$ \\
\hline $\mathrm{G}: \mathrm{C} \rightarrow \mathrm{T}: \mathrm{A}$ & 3 & $6 \%$ & 3 & $4 \%$ \\
\hline $\mathrm{G}: \mathrm{C} \rightarrow \mathrm{C}: \mathrm{G}$ & 1 & $2 \%$ & & \\
\hline $\mathrm{A}: \mathrm{T} \rightarrow \mathrm{T}: \mathrm{A}$ & 22 & $45 \%$ & 33 & $48 \%$ \\
\hline $\mathrm{A}: \mathrm{T} \rightarrow \mathrm{C}: \mathrm{G}$ & 7 & $14 \%$ & 9 & $13 \%$ \\
\hline \multicolumn{5}{|l|}{ Frameshifts } \\
\hline$-1 b p$ & 2 & $4 \%$ & & \\
\hline
\end{tabular}

Others (possibly splicing mutations) ${ }^{\ddagger}$

$-339 \mathrm{bp} \quad 1$

$+309 \mathrm{bp} \quad 1$

$-134 \mathrm{bp} \quad 1$

$+90 \mathrm{bp}$

$+31 \mathrm{bp}$

Total

55

\section{9}

*Number of "independent" mutations. Mutations found in more than one clone from a single rat were not considered to be "independent". "Expressed as the percentage among basepair substitutions and frameshifts. ${ }^{\ddagger}$ These types of mutations were not detected in the analysis used for Hprt mutations. ${ }^{\S} \mathrm{Hprt}$ mutation data are from Ref. 37.
In theory, treatment-induced Pig- $a$ mutant RBCs could originate in any of the nucleated precursors of RBCs, from pluripotent stem cells to nucleated erythroid precursor cells in the last stages of differentiation. In experiments measuring mutant manifestation in peripheral blood after treatment of rats with the five mutagens (ENU, 7,12-dimethylbenz[ $a$ ]anthracene, $N$ methyl- $N$-nitrosourea, 4-nitroquinoline- $N$-oxide, benzo $[a]$ pyrene), all mutagens increased the frequencies of both CD59-deficient (Pig- $a$ mutant) RBCs and RETs, but the frequency of mutant RETs was always leading (achieving maximum responses at around 2 weeks posttreatment), and the frequency of mutant RBCs was always trailing (achieving maximum responses at around 2 months post-treatment) (22). These kinetics are expected of mutagenized cells that transit from the bone marrow (mainly as RETs) to populate the large pool of circulating RBCs (mainly in the form of mature NCEs that initially have a relatively low background mutant frequency). The rate of mutant manifestation in the total RBC pool is probably influenced heavily by the turnover time of mature cells in rat peripheral blood, about $8-9$ weeks $(23,24)$.

Further observations regarding induced Pig- $a$ mutant frequencies is their persistence. Rats exposed acutely to ENU exhibit high mutant RET and total RBC frequencies over prolonged periods $(22,25)$. These observations on the persistence of Pig-a mutants in peripheral blood are at least consistent with the incidence of GPI anchordeficient RBCs reflecting the mutant frequencies in very long-lived committed progenitor and/or pluripotent stem cells. This persistence of the induced mutant yield is similar to what occurs in transgenic systems, whose mutational targets are regarded as having a neutral (or no) phenotype in vivo (26). The conclusion that the Pig$a$ gene is functionally neutral, at least in hematopoetic cells, is supported by results using Pig- $a$ conditional knockout mice. In these studies, mice mosaic for Pig- $a$ mutation displayed relatively stable frequencies of Pig- $a$ mutant and wild-type cells $(27,28)$.

In addition, Miura et al. reported that the effects of split doses of ENU were additive (25). That is, a single administration of ENU (e.g., $35.6 \mathrm{mg} / \mathrm{kg}$ ) produced approximately the same maximum frequency of C59deficient RBCs as dividing the total dose into 4 smaller weekly treatments (e.g., 4 doses of $8.9 \mathrm{mg} / \mathrm{kg}$ ). An additive effect may be advantageous when integrating the Pig- $a$ gene mutation assay into the conventional general toxicology study, e.g., 28-day or 90-day repeat-dose toxicity study. In contrast to the micronucleus assay or the comet assay, which generally are sensitive only to damage produced in a relatively small window of time before the sampling time, the Pig- $a$ gene mutation assay potentially can take advantage of the cumulative damage produced during an extended animal exposure. 


\section{Validation of the Methodology}

Before the Pig- $a$ gene mutation assay is adopted as a gene mutation assay that is part of the test battery for genotoxic hazard identification, much more information must be generated about how best to conduct it. Basic information on the elements making up a standard protocol and guidelines must be developed, including the optimum number of animals, dosing and sampling schedule, the number of cells interrogated, data analysis, criteria for positive and negative responses, and the limits of toxicity in the assay. Also, more information on the responses of various classes of agents in the assay must be generated and mutant cells identified by marker-deficient phenotype should be confirmed by the analysis of genetic material (i.e., sequencing the Pig$a$ gene). Eventually, a formal validation of the assay will have to be organized. To address some of these issues, an international multi-laboratory trial has been initiated (29-35). This inter-laboratory trial placed an initial focus on evaluating the portability of flow cytometric methodology (i.e., mutant RET and mutant total RBC scoring). The early work involved acute treatment of rats with predefined doses of ENU and collection of serial blood specimens at predetermined time-points. By expanding the number of expert laboratories that are proficient with this assay, this international trial is still ongoing and it should be possible to rapidly acquire information on experimental variables and additional chemicals that require further study.

In Japan, collaborative work on the Pig- $a$ gene mutation assay was conducted as a project supported by the Japan Health Sciences Foundation. The participating laboratories conducted the PIGRET assay to examine its transferability and reproducibility and to compare the response in this assay with those of the RBC Pig- $a$ assay (36). The finding suggested that the PIGRET assay may detect the in vivo mutagenicity of test chemicals earlier than the RBC Pig- $a$ assay. By expanding its participants, the Japanese multi-laboratory research of the PIGRET assay is currently ongoing by the collaborative research group in the JEMS, and recent advances by the group would appear in this special issue of Genes and Environment.

\section{Conclusion}

As regulatory testing schemes move beyond simple hazard identification and put more emphasis on in vivo responses as a better measure of human risk, an in vivo gene mutation assay becomes more valuable. Two distinct strategies for the Pig- $a$ gene mutation assay used peripheral blood have been developed, one using flow cytometry and the other using limiting-dilution cloning. The relatively fast, cost-effective way that data can be produced, and the ability to perform multiple samplings and mutation assays on individual animals, make the flow cytometry strategy for the Pig- $a$ assay on RETs and total RBCs an attractive possibility for developing detailed mutagenicity data. Although a large amount of information must be gathered on assay performance, progress toward the goal in the last few years has been rapid, and we can remain optimistic that the Pig- $a$ gene mutation assay will become a useful assay for measuring in vivo gene mutation. The cloning assay is resource intensive, therefore, the flow cytometric procedures are preferred for routine analysis of mutant frequency. The advantage of the cloning assay, however, is in-depth analyses of the mutant genotype (mutational spectra analysis).

Conflicts of Interest: The author declares that there are no conflicts of interests.

\section{References}

1 Cimino MC. Comparative overview of current international strategies and guidelines for genetic toxicology testing for regulatory purposes. Environ Mol Mutagen. 2006; 47: 362-90.

2 Snyder RD, Green JW. A review of the genotoxicity of marketed pharmaceuticals. Mutat Res. 2001; 488: 151-69.

3 Kirkland D, Aardema M, Henderson L., Muller L. Evaluation of the ability of battery of three in vitro genotoxicity tests to discriminate rodent carcinogens and noncarcinogens I. Sensitivity, specificity and relative predictivity. Mutat Res. 2005; 584: 1-256.

4 Kawagoe K, Takeda J, Endo Y, Kinoshita T. Molecular cloning of murine Pig-a, a gene for GPI-anchor biosynthesis, and demonstration of interspecies conservation of its structure, function, and genetic locus. Genomics. 1994; 23: 566-74.

5 Watanabe R, Inoue $\mathrm{N}$, Westfall B, Taron $\mathrm{CH}$, Orlean P, Takeda $J$, et al. The first step of glycosylphosphatidylinositol biosynthesis is mediated by a complex of PIG-A, PIG-H, PIG-C and GPI1. EMBO J. 1998; 17: 877-85.

6 Nishimura J, Murakami Y, Kinoshita T. Paroxysmal nocturnal hemoglobinuria: An acquired genetic disease. Am J Hematol. 1999; 62: 175-82.

7 Brodsky RA, Hu R. PIG-A mutations in paroxysmal nocturnal hemoglobinuria and in normal hematopoiesis. Leuk Lymphoma. 2006; 47: 1215-21.

8 Low MG. The glycosyl-phosphatidylinositol anchor of membrane proteins. Biochim Biophys Acta. 1989; 988: 427-54.

9 Cross GA. Glycolipid anchoring of plasma membrane proteins. Annu Rev Cell Biol. 1990; 6: 1-39.

$10 \mathrm{Hu}$ R, Mukhina GL, Lee SH, Jones RJ, Englund PT, Brown $\mathrm{P}$, et al. Silencing of genes required for glycosylphosphatidylinositol anchor biosynthesis in Burkitt lymphoma. Exp Hematol. 2009; 37: 423-34.

11 Takeda J, Miyata T, Kawagoe K, Iida Y, Endo Y, Fujita $\mathrm{T}$, et al. Deficiency of the GPI anchor caused by somatic mutation of PIG-A gene in paroxysmal nocturnal 
hemoglobinuria. Cell. 1993; 72: 703-11.

12 Hall SE, Rosse WF. The use of monoclonal antibodies and flow cytometry in the diagnosis of paroxysmal nocturnal hemoglobinuria. Blood. 1996; 87: 5332-40.

13 Araten DJ, Nafa K, Pakdeesuwan K, Luzzatto L. Clonal population of hematopoietic cells with paroxysmal nocturnal hemoglobinuria genotype and phenotype are present in normal individual. Proc Natl Acad Sci USA. 1999; 96: 5209-14.

14 Miura D, Dobrovolsky VN, Kasahara Y, Katsuura Y, Heflich RH. Development of an in vivo gene mutation assay using the endogenous Pig-A gene: I. Flow cytometic detection of CD59-negative peripheral red blood cells and CD48-negative spleen T-cells from the rat. Environ Mol Mutagen. 2008; 49: 614-21.

15 Bryce S, Bemis J, Dertinger S. In vivo mutation assay based on the endogenous Pig-a locus. Environ Mol Mutagen. 2008; 49: 256-64.

16 Kimoto T, Suzuki K, Kobayashi XM, Dobrovolsky VN, Heflich RH, Miura D, et al. Manifestation of Pig-a mutant bone marrow erythroids and peripheral blood erythrocytes in mice treated with N-ethyl-N-nitrosourea: direct sequencing of Pig-a cDNA from bone marrow cells negative for GPI-anchored protein expression. Mutat Res. 2011; 723: 36-42.

17 Kimoto T, Chikura S, Suzuki K, Kobayashi XM, Itano Y, Horibata K, et al. Further development of the rat Piga mutation assay: measuring rat Pig-a mutant bone marrow erythroids and a high throughput assay for mutant peripheral blood reticulocytes. Environ Mol Mutagen. 2011; 52: 774-83.

18 Miura D, Dobrovolsky VN, Mittelstaedt RA, Kasahara Y, Katsuura Y, Heflich RH. Development of an in vivo gene mutation assay using the endogenous Pig-A gene; II. Selection of Pig-A mutant rat spleen T-cells with Proaerolysin and sequencing Pig-A cDNA from the mutants. Environ Mol Mutagen. 2008; 49: 622-30.

19 Parker MW, van der Groot FG, Buckley JT. Aerolysinthe ins and outs of a model channel-forming toxin. Mol Microbiol. 1996; 19: 205-12.

20 Brodsky RA, Mukhina GL, Nelson KL, Lawrence RS, Jones RJ, Buckley JT. Resistance of paroxysmal nocturnal hemoglobinuria cells to the glycosylphosphatidylinositol-binding toxin aerolysin. Blood. 1999; 93: 1749-56.

21 Miura D, Shaddock JG, Mittelstaedt RA, Dobrovolsky VN, Kimoto T, Kasahara Y, et al. Analysis of mutations in the Pig-a gene of spleen T-cell from N-ethyl-Nnitrosourea-treated Fisher 344 rats. Environ Mol Mutagen. 2011; 52: 419-23.

22 Phonethepswath S, Franklin D, Torous DK, Bryce SM, Bemis JC, Raja S, et al. Pig-a mutation: Kinetics in rat erythrocytes following exposure to five prototypical mutagens. Toxicol Sci. 2010; 114: 59-70.

23 Derelanko MJ. Determination of erythrocyte life span in F-344, Wistar, and Sprague-Dawley rats using a modification of the $\left[{ }^{3} \mathrm{H}\right]$ diisopropylfluorophosphate $\left(\left[{ }^{3} \mathrm{H}\right] \mathrm{DFP}\right)$ method. Fundam Appl Toxicol. 1987; 9: 271-6.

24 Smith JE. Comparative biology and toxicology of the erythron. In: Bloom JC, editor. Comprehensive Toxicology, Vol. 4. Toxicology of the hematopoietic system. New York: Elsevier; 1997. p. 107-21.

25 Miura D, Dobrovolsky VN, Kimoto T, Kasahara Y, Heflich RH. Accumulation and persistence of Pig-A mutant peripheral red blood cells following treatment of rats with single and split doses of N-ethyl-N-nitrosourea. Mutat Res. 2009; 677: 86-92.

26 Thybaud V, Dean S, Nohmi T, de Boer J, Douglas GR, Glickman BW, et al. In vivo transgenic mutation assays. Mutat Res. 2003; 540: 141-51.

27 Keller P, Tremml G, Rosti V, Bessler M. X inactivation and somatic cell selection rescue female mice carrying a Piga-null mutation. Proc Natl Acad Sci USA. 1999; 96 : 7479-83.

28 Rosti V. Murine models of paroxysmal nocturnal hemoglobinuria. Ann N Y Acad Sci. 2002; 963: 290-6.

29 Dertinger SD, Phonethepswath S, Weller P, Nicolette J, Murray J, Sonders P, et al. International Pig-a gene mutation assay trial: Evaluation of transferability across 14 laboratories. Environ Mol Mutagen. 2011; 52: 690-8.

30 Lynch AM, Giddings A, Custer L, Gleason C, Henwood A, Aylott M, et al. International Pig-a gene mutation assay trial (Stage III): Results with N-methyl-Nnitrosourea. Environ Mol Mutagen. 2011; 52: 699-710.

31 Shi J, Krsmanovic L, Bruce S, Kelly T, Paranjpe M, Szabo $\mathrm{K}$, et al. Assessment of genotoxicity induced by 7,12dimethylbenz(a)anthracene or diethylnitrosamine in the Pig-a, micronucleus and Comet assays integrated in 28-day repeat dose studies. Environ Mol Mutagen. 2011; 52: 711-20.

32 Cammerer Z, Bhalli JA, Cao X, Coffing SL, Dickinson D, Dobo KL, et al. Report on Stage III Pig-a mutation assays using N-ethyl-N-nitrosourea-Comparison with other in vivo genotoxicity endpoints, Environ Mol Mutagen. 2011; 52: 721-30.

33 Bhalli JA, Shaddock JG, Pearce MG, Dobrovolsky VN, Cao X, Heflich RH, et al. Report on Stage III Pig-a mutation assays using benzo[a]pyrene. Environ Mol Mutagen. 2011; 52: 731-7.

34 Stankowski Jr. LF, Roberts DJ, Chen H, Lawlor T, McKeon $\mathrm{M}$, Murli $\mathrm{H}$, et al. Integration of Pig-a, micronucleus, chromosome aberration, and Comet assay endpoints in a 28-day rodent toxicity study with 4-nitroquinoline-1-oxide. Environ Mol Mutagen. 2011; 52: 738-47.

35 Dertinger SD, Phonethepswath S, Weller P, Avlasevich S, Torous DK, Mereness JA, et al. Interlaboratory Pig-a gene mutation assay trial: Studies of 1,3-propane sultone with immunomagnetic enrichment of mutant erythrocytes. Environ Mol Mutagen. 2011; 52: 748-55.

36 Kimoto T, Horibata K, Chikura S, Hashimoto K, Itoh S, Sanada $\mathrm{H}$, et al. Interlaboratory trial of the rat Pig-a mutation assay using an erythroid marker HIS49 antibody. Mutat Res. 2013; 755 126-34.

37 Mittelstaedt RA, Smith BA, Heflich RH. Analysis of in vivo mutation induced by $\mathrm{N}$-ethyl-N-nitrosourea in the hprt gene of rat lymphocytes. Environ Mol Mutagen. 1995; 26: 261-9. 